\title{
GERAKAN SYI'AH MEMPERTAHANKAN EKSISTENSINYA DALAM KONSTELASI POLITIK KEAGAMAAN DI INDONESIA
}

\author{
Rifa'i Abubakar \\ Universitas Muhammadiyah Yogyakarta \\ E-mail: staimsyogyakarta@yahoo.co.id \\ Syamsul Anwar \\ Universitas Islam Negeri Sunan Kalijaga Yogyakarta \\ Haedar Nashir \\ Universitas Muhammadiyah Yogyakarta
}

\section{Abstrak}

Dinamika Gerakan Syi'ah Mempertahankan Eksistensinya Dalam Konstelasi Politik Keagamaan di Indonesia" adalah penelitian untuk disertasi, bertujuan untuk mengemukakan (1). Faktor yang mempengaruhi eksistensi Syi'ah di Indonesia dan bentuk eksistensi Syi'ah, (2).Unsur gerakan Syi'ah mempertahankan Eksistensinya (3). Dinamika konflik dan integrasi. Pengumpulan data dilakukan dengan wawancara, pengamatan dan penelusuran dokumen Syi'ah di Indonesia. Temuan penelitian ini didasarkan pada analisis data untuk menjawab problem penelitian yaitu (1). Gerakan Syi'ah mempertahankan eksistensinya dalam konstelasi politik keagamaan di Indonesia memperjuangkan pembentukan masyarakat Syi'ah dan negara Islam Syi'ah dengan model gerakan intelektual, gerakan spiritual dan gerakan ideologis. Syi'ah eksis dalam konstelasi politik keagamaan di Indonesia, karena Syi'ah mampu mengkonstruksikan dirinya untuk bertahan dengan memperbesar kontribusi dalam membangun sumber daya manusia Indonesia yang cukup signifikan dan memperkokoh soliditas internal dan membangun jaringan kerjasama dengan kelompok Islam lainnya. Secara teologis bahwa paham keagamaan Islam Syi'ah tidak seluruhnya berbeda dengan paham keagamaan Islam Sunni. Ada ajaran Syi'ah yang bersentuhan dengan amaliyah Islam Sunni tradisional. Syi'ah membangun jaringan struktural, hidup dalam budaya masyarakat majemuk yang toleran, mampu beradaptasi dengan perbedaan. Dinamika konflik telah mewarnai gerakan Syi'ah, akan tetapi daya integrasinya lebih kuat dari daya konflik. Secara sosiologis, karena pergulatan 
Rifa'i Abubakar, Syamsul Anwar dan Haedar Nashir : Gerakan Syi'ah

Mempertahankan Eksistensinya dalam Konstelasi Politik Keagamaan Di Indonesia

Syi'ah di Indonesia baik dalam bidang pendidikan, kaderisasi, sosial, agama, budaya maupun politik telah berlangsung lama, semakin terbuka dan berkembang. Akulturasi budaya Syi'ah dengan budaya Islam Indonesia mampu merekatkan hubungan kedua komunitas islam tersebut, demikian juga pembauran antara orang Syi'ah dengan orang Islam Sunni dalam pergaulan. Kemampuan orang-orang Syi'ah berintegrasi dengan Sunni dengan senantiasa menerapkan akhlak mulia, dengan jalinan pola hubungan yang baik antara tokoh Syi'ah dengan non Syi'ah, menjadikan Syi'ah dapat diterima sebagai komunitas Islam yang tidak berbeda dengan Islam Sunni. Beberapa spek yang eksis adalah kelembagaan, aspek ajaran atau paham keagamaan, keanggotaan dan aktivitas Syi'ah yang berkembang.

Kata Kunci: Syi'ah, Eksistensi, Konstelasi Politik, Keagamaan.

\section{Abstract}

Dynamic of Shia Movement in Keeping Its Existence in Religious Politic Constellation in Indonesia". This research was intended to present (1) factors influencing existence of Shia in Indonesia and form of Shia existence, (2) element of Shia movement in defending its existence, (3) dynamic of conflict and integration, and (4) Shia in Indonesian political system and religious political practice. Data was collected with interview, observation and tracing documents on Shia in Indonesia. Findings of the research were based on analysis of data to answer research questions. Shia movement kept its existence in religious political constellation in Indonesia and fought shaping Shia society and Shia Islamic state with intellectual movement, spiritual movement, and ideological movement. Shia existed in Indonesian religious political constellation because Shia can construct its self to defend by making great contribution in developing human resource, strengthening internal solidity and developing cooperation with other Islamic groups. In theological perspective, not all Shia views of Islam are different from Sunni Islamic religious view. There is Shia teaching that touch with traditional Sunni Islam amaliyah. Shia developed structural network, live in tolerant plural society culture, and can adapt to difference. Conflict dynamic have colored Shia movement but its integration power was stronger than conflict power. In sociological term, Shia struggle in Indonesia in education, creating cadre, social, religion, cultural and political field have run long time with increasingly open and developing characteristic. Acculturation of 


\begin{abstract}
Rifa’i Abubakar, Syamsul Anwar dan Haedar Nashir : Gerakan Syi'ah Mempertahankan Eksistensinya dalam Konstelasi Politik Keagamaan Di Indonesia
\end{abstract}

Shia culture and Indonesia Islamic culture can bind relationship between both Islamic communities. Mix between Shia people and Sunni people also occurred in their intercourse. Capability of Shia people to integrate with Sunni by applying good character, with good association network between Shia figure and non Shia figure made Shia acceptable as Islamic community not different from Sunni.

In the New Order, Shia people did Taqiyah to avoid pressure and threat from other Islamic group. In addition, the New Order regime was considered authoritarian and repressive toward certain society group. After more democratic Reformation Order, Shia people showed their existence. Islamic people prize tolerance and acknowledge and respect human rights regulated in the 1945 Constitution. There are no positive laws that deny presence of Shia in Indonesia. In addition, Amman Declaration, Makah Declaration and Al-Azhar Syarif fatwa confirm that Shia is inseparable part of Islamic people. Some existing aspects are organization, theological teaching and membership. Shia people in Indonesia grew from one million to 2,500,000 that were distributed in 33 provinces in Indonesia. Activity of Shia also grew and developed.

Keywords: Shi'a, Existence, Political Constellation, Religious.

\title{
I. PENDAHULUAN
}

\section{A. Latar Belakang}

Menurut A. Hasymi, Syi'ah sudah masuk ke Indonesia sejak masa awal masuknya Islam, yaitu 1 Muharram 225 H/840 M. Sebuah kapal layar yang datang dari teluk Kambay Gujarat yang membawa angkatan dakwah berjumlah 100 orang kebanyakan tokoh Syi'ah Arab, Persia dan Hindi di bawah pimpinan Nakhoda Khalifah berlabuh di Bandar Perlak Aceh. 129 Sejak tahun 225 H Syi'ah telah membangun kerajaan Islam di Perlak. Akan tetapi kemudian ajaran Islam

129 A. Hasymy, Sejarah Masuk dan Berkembangnya Islam di Indonesia, (Bandung: PT Al-Ma'arif, 1989), hlm. 146, 156, lihat juga M.Yunus Jamil, Tawarikh Raja-raja Kerajaan Aceh, (Banda Aceh: Ajdam I Iskandarmuda, 1968), hlm. 6-8. 
Rifa'i Abubakar, Syamsul Anwar dan Haedar Nashir : Gerakan Syi'ah Mempertahankan Eksistensinya dalam Konstelasi Politik Keagamaan Di Indonesia

Sunni menyebar di kalangan Syi'ah yang tidak disukai mereka, berakibat timbul beberapa kali perang saudara. Dalam peperangan terakhir terjadi perdamaian dengan kesepakatan pembagian wilayah kekuasaan. Oleh karena itu kehadiran Syi'ah di tanah air ini tidak sepi dari hujatan dan tuntutan terhadap pembubaran Syi'ah.

Pada masa Orde Lama dan Orde Baru, Syi'ah tidak menampakan diri secara fisik, mereka lebih memilih menggunakan taqiyah sebagai salah satu strategi agar dapat diterima oleh umat Islam Indonesia. Tetapi kemudian sejak era reformasi yang sejalan dengan tumbuh dan berkembangnya pemahaman Islam yang semakin kuat dan munculnya gerakan Islam fundamentalis dan Salafi yang memperjuangkan Islam yang sesuai dengan al-Qur'an dan Sunnah Rasul, sebagaimana yang diamalkan para salafus saleh, melalui organisasi seperti Hizbut Tahrir Indonesia, Majelis Mujahidin Indonesia, Forum Pembela Islam dan lain-lain, maka kemunculan Syi'ah secara fisik mendapat penolakan yang cukup keras. Mengerasnya penolakan terhadap Syi'ah Indonesia sejalan dengan gerakan Salafiyah yang tumbuh pada tahun 1980-an dan semakin menguat pada era reformasi baik yang berorientasi keagamaan murni, maupun politik yang cenderun radikal, karena para pengikutnya terkadang melakukan aksi-aksi yang bersifat merusak dan menghancurkan segala hal yang menurut mereka tidak sesuai dengan ajaran Islam, seperti menghancurkan tempat-tempat maksiat. Gerakan-gerakan Salafiyah yang berkembang pada era tahun 1980-an dan 1990an di Indonesia, berusaha untuk memahami dan menjalankan akidah dan praktik hidup Islam mengikuti Nabi serta generasi Salaf al-Shalih dengan sebenar-benarnya. Sebagaimana 
Rifa'i Abubakar, Syamsul Anwar dan Haedar Nashir : Gerakan Syi'ah Mempertahankan Eksistensinya dalam Konstelasi Politik Keagamaan Di Indonesia

gerakan Salafiyah Muhammadiyah dan lain-lain pada awal abad ke-20 yang menggelorakan kembali pada al-Qur'an dan Sunnah Nabi serta menentang segala bentuk syirik, bid'ah, takhayul, dan khurafat. ${ }^{130}$ Namun, gerakan Salafiyah era baru tersebut memiliki ciri sebagai berikut: Pertama, lebih menekankan pada penegakan syari'at Islam secara formalistik daripada perhatian terhadap masalah lainnya. Kedua, kendati menggunakan simbol Ahlus Sunnah, kelompok ini cenderung memandang Nahdlatul Ulama yang juga menganut paham Ahlussunnah Waljamaah sebagai ahli bidah, bahkan juga Muhammadiyah. Ketiga, memiliki sifat radikal atau termasuk dalam kategori fundamentalisme Islam, walaupun lebih condong pada fundamentalisme skripturalis, karena lebih menekankan pada paham dan praktik keagamaan yang murni dan keras. Keempat, karena wataknya yang formalistik dan fundamentalistik, maka selain bergerak di bidang dakwah, terdapat kecenderungan gerakan Salafiyah ini memasuki gerakan politik, artinya tidak semata-mata gerakan keagamaan. Kelima, mengambil corak gerakan (harakah) di selain dakwah murni sebagai gerakan murni keagamaan, karena itu Salafi yang bercorak dakwah ini menolak atau tidak memasuki wilayah politik, termasuk dalam menggagas negara Islam atau Khilafah Islam sebagaimana dilakukan Hizbut Tahrir dan Majelis Mujahidin Indonesia. Keenam, cara mempraktikkan Islam sangat dipengaruhi Wahabi (Wahabiyyah), yang mementingkan pemurnian secara skriptural, menolak segala bentuk takhayul, bid'ah, dan

130 Haedar Nashir, Islam Syariat: Reproduksi Salafiyah Ideologis di Indonesia,(Bandung: PT Mizan Pustaka, 2013), hlm. 169. 
Rifa'i Abubakar, Syamsul Anwar dan Haedar Nashir : Gerakan Syi'ah Mempertahankan Eksistensinya dalam Konstelasi Politik Keagamaan Di Indonesia

khurafat, dan menolak pembaruan, sehingga sering berhadapan dengan arus-utama Islam di negeri ini. ${ }^{131}$

Oleh karena itulah MUI Jawa Timur mengeluarkan Fatwa Nomor Kep-01/SKF-MUI/JTM/2012 tanggal 21 Januari 2012 mengukuhkan dan menetapkan sejumlah keputusan MUI Daerah yang menyatakan bahwa ajaran Syi'ah Imamiyah atau Itsna Asyariah (Mazhab Ahlulbait) serta ajaran-ajaran yang mempunyai kesamaan dengan paham Syi'ah Imamiyah atau Itsna Asyariah adalah sesat dan menyesatkan, dan penggunaan istilah Ahlulbait untuk pengikut Syi'ah adalah bentuk pembajakan kepada Ahlulbait Rasulullah.

Puncak perlawanan terhadap Syi'ah telah melahirkan suatu gerakan Aliansi Nasional Anti Syi'ah (ANNAS) yang dideklarasikan di Bandung. Berbagai elemen masyarakat dan ormas-ormas Islam seluruh Indonesia bergabung dalam aliansi ini yang menuntut dikeluarkannya fatwa sesat terhadap Syi'ah oleh MUI pusat dan menuntut kepada pemerintah Indonesia untuk melarang ajaran Syi'ah dan membubarkan ormas Syi'ah secara nasional. 132 Walaupun banyak penolakan terhadap keberadaan Syi'ah melalui berbagai gerakan penentangan yang dilakukan oleh umat Islam(Sunni) bahkan secara resmi melalui organisasi masyarakat, yaitu MUI secara nasional telah mengeluarkan Fatwa tentang kesesatan Syi'ah, namun Syi'ah tetap eksis bahkan cenderung mengalami perkembangan. ${ }^{133}$

131 Haedar Nashir, Islam Syariat: Reproduksi Salafiyah Ideologis............., hlm. 170.

132 Abdul Chair Ramadhan, Membangun Politik Hukum Sistem Ketahanan Nasional Terhadap Ancaman Ekspansi Ideologi Transnasional Syi'ah Iran, (Surakarta: Disertasi Program Pascasarjana Program Doktor Ilmu Hukum UNS, 2015, Tidak diterbitkan), hlm.138.

133 Indikasi perkembangan Syi'ah adalah banyak yayasan yang berdiri, penerbitan, lembaga pendidikan. 
Rifa'i Abubakar, Syamsul Anwar dan Haedar Nashir : Gerakan Syi'ah Mempertahankan Eksistensinya dalam Konstelasi Politik Keagamaan Di Indonesia

\section{B. Rumusan Masalah}

Masalah penelitian dapat dirumuskan : Pertama, mengapa dan dalam aspek apa saja Syi'ah eksis dan berkembang di tengah mayoritas penganut Sunni dalam konstelasi politik keagamaan di Indonesia? Kedua,bagaimana dinamika pergulatan Syi'ah dalam mempertahankan eksistensinya dalam konstelasi politik keagamaan di Indonesia?

\section{Tujuan dan Kegunaan Penelitian}

Tujuan penelitian adalah mendeskripsikan: Pertama, Faktor-faktor penyebabkan Syi'ah eksis dalam konstelasi politik keagamaan Indonesia dan aspek Syi'ah yang eksis. Kedua, Dinamika pergulatan Syi'ah mempertahankan eksistensinya dalam konstelasi politik keagamaan di Indonesia.

\section{Kerangka Teori}

Interaksi sosial adalah suatu hubungan antara dua individu atau lebih dimana kelakuan individu yang satu mempengaruhi, mengubah atau memperbaiki kelakuan individu yang lain. ${ }^{134}$ Interaksi sosial adalah kunci dari semua kehidupan sosial karena tanpa interaksi sosial tidak mungkin ada kehidupan bersama. ${ }^{135}$ Interaksi sosial terjadi apabila terpenuhi dua syarat yaitu kontak sosial dan komunikasi. 136 Interaksi sosial dapat berlangsung dalam berbagai bentuk yaitu: Pertama, Co-operation yaitu interaksi sosial dalam bentuk kerjasama antara orang perorang atau kelompok hlm.25.

134 Abu Ahmadi, Psikologi Sosial, (Jakarta: Rineka Cipta, 1999),

135 Kimbal Young dan Raymond W, Mack, Sociologi and Social Life, (New York: American Book Company, 1959), hlm. 137.

136 Soerjono Soekanto, Faktor-faktor Dasar Interaksi Sosial dan Kepatuhan pada Hukum, (Hukum Nasional Nomor 25, 1974), hlm. 491 
Rifa'i Abubakar, Syamsul Anwar dan Haedar Nashir : Gerakan Syi'ah Mempertahankan Eksistensinya dalam Konstelasi Politik Keagamaan Di Indonesia

manusia untuk mencapai tujuan bersama. Kedua, Assimilation (asimilasi) merupakan interaksi sosial melalui usaha-usaha untuk mengurangi perbedaan yang terdapat antara orang perorangan atau kelompok manusia juga mempertinggi kesatuan tindakan untuk mencapai kepentingan dan tujuan bersama. 137 Ketiga, Contravention pada hakikatnya adalah bentuk proses sosial yang berada antara persaingan dengan pertentangan atau pertikaian terutama ditandai adanya gejalagejala ketidakpastian atau kebencian terhadap seseorang atau kelompok orang. ${ }^{138}$ Keempat, Kompetisi adalah suatu proses sosial dimana orang perorangan atau kelompok manusia bersaing untuk mencari keuntungan melalui bidang-bidang kehidupan yang menjadi pusat perhatian publik dengan cara menarik perhatian publik atau mempertajam prasangka tanpa menggunakan kekerasan atau ancaman. Kelima, Integrasi adalah dibangunnya interdependensi yang lebih rapat antara bagian-bagian organisme hidup atau antara anggota-anggota dalam suatu masyarakat sehingga integrasi adalah proses mempersatukan masyarakat. 139 Oleh karena itu untuk menciptakan kestabilan dalam masyarakat yang majemuk diperlukan integrasi sosial. Menurut Durkheim, norma-norma masyarakat, keyakinan dan nilai-nilai membentuk sebuah kesadaran kolektifdan kesadaran kolektif inilah yang mengikat orang secara bersama-sama untuk terciptanya integrasi sosial. Keenam, Akomodasi adalah suatu proses yang menunjuk pada suatu keadaan yaitu suatu kenyataan adanya suatu

${ }^{137}$ Gillin and Gillin, Cultural Sociology......., hlm. 517.

138 Soerjono Soekanto, Sosiologi Suatu Pengantar, Edisi keempat, (Jakarta: PTRaja Grafindo Persada, 1997), hlm. 94-97.

139 Agus Mulyono, Umat Beragama di Kota Batam: Antara Potensi Integrasi dan Konflik, dalam Harmoni, volume IX, Nomor 35 Juli-September 2010, Jurnal Multikultural dan Multi religius, hlm. 155. 


\begin{abstract}
Rifa'i Abubakar, Syamsul Anwar dan Haedar Nashir : Gerakan Syi'ah Mempertahankan Eksistensinya dalam Konstelasi Politik Keagamaan Di Indonesia

keseimbangan dalam interaksi antara orang perorangan dan kelopmok-kelompok manusia sehubungan dengan normanorma sosial dan nilai-nilai sosial yang berlaku dalam masyarakat. ${ }^{140}$ Ketujuh, Konflik adalah pertentangan antara anggota atau antara kelompok dalam masyarakat yang bersifat menyeluruh yang disebabkan oleh beberapa perbedaan: yaitu perbedaan individu, perbedaan pola budaya, perbedaan status sosial, perbedaan kepentingan dan terjadinya perubahan sosial.
\end{abstract}

\title{
E. Metode Penelitian
}

Jenis penelitian ini adalah penelitian kualitatif untuk menemukan esensi dari sebuah fenomena. ${ }^{141}$ Sumber primer adalah tokoh-tokoh Syi'ah Indonesia yang banyak mengetahui tentang Syi'ah yang dijadikan sebagai informan kunci. Demikian juga dokumen yang memuat data tentang Syi'ah Indonesia yang berkaitan dengan data penelitian yang dibutuhkan dijadikan sebagai sumber data primer. Untuk memperoleh data dari sumber primer dilakukan dengan wawancara mendalam. Penarikan sampel dalam penelitian ini menggunakan (1). Purposive Sampling. Purposive sampling yang sering disebut dengan sampling pertimbangan.

Snowball Sampling. Snowball sampling adalah teknik sampling yang jumlah informan pada awalnya sedikit kemudian anggota informan mengajak temannya untuk dijadikan sampel, sehingga jumlah sampel semakin banyak. Teknik pengumpulan data. Pengumpulan data dengan Wawancara mendalam (Indepth interview) serta observasi secara

140 Soerjono Soekanto, Sosiologi ..., hlm. 95.

141 Noeng Muhadjir, Metodologi Penelitian Kualitatif, Edisi III, (Yogyakarta: Rake Sarasin, 1998), hlm. 5. 
Rifa'i Abubakar, Syamsul Anwar dan Haedar Nashir : Gerakan Syi'ah Mempertahankan Eksistensinya dalam Konstelasi Politik Keagamaan Di Indonesia

langsung, 142 dokumentasi, 143 Teknik Analisis data. Teknik analisis data yang digunakan dalam penelitian ini adalah analisis kualitatif. Teknik analisis kualitatif adalah teknik yang mendasarkan pada data kualitatif atau data yang merupakan wujud dari kata-kata. ${ }^{144}$ Jika penelitian kuantitatif mengukur kesahihan penelitian dengan angka-angka dan bersifat verifikatif, maka penelitian kualitatif bersifat eksploratif yaitu mencari data dengan cara mengeksplorasi objek penelitian secara holistik (menyeluruh). 145 dan mendalam untuk memperoleh kesimpulan yang mendalam dan berkualitas.

\section{PEMBAhASAN}

Setiap gerakan sosial, politik, kebudayaan dan massa tidak lepas dari faktor-faktor yang selalu melingkari gerakan tersebut yaitu: Pertama, setting (sejarah) sosial politik lahirnya gerakan tersebut baik lingkup global maupun nasional. Kedua, aktor perintis berdiri gerakan. Ketiga, sistem nilai yang dianut oleh gerakan dan diperjuangkan. Keempat, kegiatan penerimaan, pembinaan, pemutusan anggota, sistem kepemimpinan dan hubungan sosial. Kelima, pengikut setia gerakan yang selalu patuh kepada pemimpin. Keenam, simbol

142 Burhan M. Bungin, Penelitian Kualitatif: Komunikasi, Ekonomi, Kebijakan Publik, dan Ilmu Sosial, (Jakarta: Kencana Prenama Media Group, 2007), hlm. 52.

143Dokumen, adalah cacatan tertulis tentang berbagai kegiatan atau peristiwa pada masa lalu. Lihat W. Gulo, Metodologi Penelitian, (Jakarta: Grasindo, 2004), hlm.123, lihat juga Sotirios Sarantakos, Social Research, (Melbourne: Mac Millan Education Australia PTY LTD, 1993), hlm. 206. Dokumentasi adalah usaha pencarian data mengenai variable yang berupa catatan, transkrip, buku, notulen rapat dll, Suharsimi Arikunto, Prosedur Penelitian Suatu Pendekatan Praktik (Jakarta: Rineka Cipta, 2013), hlm. 236.

${ }^{144}$ Mathew B, . at.al, Analisis Data Kualitatif, (Jakarta: UI Press, 1992), hlm. 30.

145M. Deden Ridwan, Tradisi Baru Penelitian Agama Islam: Tinjauan Antardisiplin Ilmu (Bandung: Nuansa, 2001), hlm. 266. 
Rifa’i Abubakar, Syamsul Anwar dan Haedar Nashir : Gerakan Syi'ah Mempertahankan Eksistensinya dalam Konstelasi Politik Keagamaan Di Indonesia

kebudayaan. ${ }^{146}$ (1). Setting Sosial politik. Islam Syi'ah sebagai kelompok minoritas terpinggirkan sejak kedatangannya, kurang mendapat pelayanan dan perhatian pemerintah. Sedangkan kelompok Islam Sunni yang memang mayoritas mendapat perlakuan yang baik dari Negara. Negara memfasilitasi pembangunan ribuan masjid. Lembaga pendidikan Islam Sunnimemperoleh pelayanandan fasilitasyang sangatbaik.Indonesia adalah Negaramajemuk dengan berbagai aliran kepercayaanyang jumlahnya mencapai 26 (dua puluh enam)buah yang berpredikat agama dan 156 (seratus lima puluh enam) yang berpredikat pedukunan dan perguruan kebatinan. ${ }^{147}$ Agama resmi terdiri dari Islam, Hindu, Budha, Kristen, Katolik dan Kunghu Chu. Dalam agama Islam terdapat perbedaan pemahaman keagamaan yang kemudian mengelompok menjadi Sunni, Syi'ah dan Ahmadiyah. Pemahanan Islam Sunni direpresentasikan oleh organisasi Muhammadiyah, Nahdlatul Ulama, Persis dan Ahmadiyah. Sedangkan dalam Islam Syi'ah direpresentasikan oleh organisasi Ikatan Jamaah Ahlul Bait Indonesia (IJABI) dan Ahlul Bait Indonesia (ABI). Ditengah situasi kehidupan politik dan agama yang sedemikian inilah Syi'ah mengambil peran dengan gerakan sosial dan keagamaan untuk mempertahankan eksistensinya. Gerakan Syi'ah Indonesia menggunakan dua corak, yaitu Syi'ah Politik untuk membentuk Negara Islam dan Syi'ah non politik untuk membentuk masyarakat Syi'ah.

\footnotetext{
146 Sidik Jatmika, Genk Remaja: Anak Haram Sejarah ataukah Korban Globalisasi ? (Yogyakarta: Penerbit Kanisius, 2010), hlm. 20.

${ }^{147}$ H. M. As'ad El Hafidy, Aliran-Aliran Kepercayaan dan Kebatinan di Indonesia, (Jakarta: Ghalia Indonesia, 1982), hlm.108-113. Lihat juga Rahnip M, Aliran Kepercayaan dan Kebatinan Dalam Sorotan, (Surabaya: Pustaka Progressif, 1987), hlm. 14-20.
} 
Rifa'i Abubakar, Syamsul Anwar dan Haedar Nashir : Gerakan Syi'ah Mempertahankan Eksistensinya dalam Konstelasi Politik Keagamaan Di Indonesia

Langkah utama Syi'ah Indonesia adalah: Pertama, mengkonsolidasikan semua yayasan Syi'ah dan meminimalisir perbedaan. Kedua, berupaya keberadaannya diterima oleh kalangan muslim Sunni Indonesia. Ketiga, berupaya mendirikan Marja al Taqlid sebuah institusi agama yang memiliki otoritas penuh untuk membentuk pemerintah dan konstitusi Islam. ${ }^{148}$ (2). Sistem keyakinan. Keyakinan yang dianut dan yang diperjuangkan Syi'ah adalah keyakinan yang berdasarkan al-Qur'an dan Sunnah Nabi SAW. Syi'ah memperjuangkan ajaran yang bersumber dari ahlulbait tentang Imamah. Syi'ah meyakini ajaran pokok yang mereka sebut dengan prinsip agama atau akidah aliran Syi'ah Itsna Asyariah. (2). Organisasi. Gerakan Syi'ah dilakukan melalui organisasi Ahlul Bait Indonesia (ABI) dan Ikatan Jamaah Ahlulbait Indonesia (IJABI).(3). Pengikut. Syi'ah sebagai gerakan agama telah berhasil menanamkan ajaran Syi'ah kepada umat Islam Indonesia yang mayoritas Sunni yang dibuktikan dengan semakin bertambahnya jumlah pengikut dari 1.000.000 orang pada tahun 1973 menjadi 2. 500.000 orang pada tahun 2008 menurut klaim IJABI. (4). Gerakan Syi'ah mengambil bentuk. Pertama, pendidikan merupakan suatu usaha untuk mengembangkan potensi dirinya untuk memiliki kekuatan spiritual keagamaan, kepribadian, kecerdasan dan keterampilan untuk memenuhi kebutuhan dirinya, masyarakat, bangsa dan negara. Kedua, bidang media Massa. Media cetak berbentuk ulletin seperti Al-Jawwad, Al-Ghadir dan Syi'ar aktif terbit serta jurnal yang diterbitkan secara

148 Sumber : Gerakan Islam Transnasional dan Pengaruhnya di Indonesia (di-release dan diedarkan oleh BIN)Copy dari : http: / / www.facebook.com/note.php?note_id=296656300358962 
Rifa'i Abubakar, Syamsul Anwar dan Haedar Nashir : Gerakan Syi’ah
Mempertahankan Eksistensinya dalam Konstelasi Politik Keagamaan Di Indonesia

berkala. ${ }^{149}$ Ketiga, bidang penerbitan buku. Jumlah buku yang telah diterbitkan oleh berbagai penerbit mencapai penerbit 171 judul buku oleh penulis yang berbeda. ${ }^{150}$ Keempat, bidang dakwah keagamaan. ${ }^{151}$ Kelima, bidang kaderisasi. Keenam, bidang budaya. ${ }^{152}$ Ketujuh, bidang politik.

Gerakan Syi'ah Indonesia dilakukan dalam tiga model yaitu: Pertama, model gerakan intelektual yaitu pencerahan kemampuan intelektual masyarakat melalui pemikiran bebas dan kritis. ${ }^{153}$ Kedua, model gerakan spiritual yaitu memperkuat daya spiritualitas masyarakat melalui kegiatan religius Syi'ah. Ketiga, model gerakan ideologis yakni memperkuat keyakinan masyarakat terhadap keyakinan yang dianut orang Syi'ah dan pemahaman akan keberhasilan revolusi Islam Iran tahun 1979.

Menguatnya gerakan Syi'ah di Indonesia menurut Mamduh Farhan al-Buhari karena 5 (lima) faktor, Pertama, kejahilan umat Islam tentang agama mereka sendiri. Kedua, kejahilan umat Islam tentang ajaran Syi'ah. Ketiga, strategi Syi'ah yang memanfaatkan suasana kelemahan ekonomi umat. Keempat, kelalaian tokoh-tokoh Sunni dalam menanggapi dakwah Syiłah. Kelima, kesungguhan luar biasa Syi'ah dalam menyebarluaskan

149 Farid Ahmad Okbah, Ahlussunnah Waljama'ah dan Dilema Syi'ah di Indonesia, (Jakarta: Perisai Qur'an , 2013), hlm.124.

150 Farid Ahmad Okbah, Ahlussunnah Waljama'ah dan Dilema Syi'ah....., hlm. 114-124. hlm.77-78.

${ }^{151}$ Disarikan dari Skripsi Ansori, Syi'ah di Kabupaten Sleman......., 152Sumber data: Sekilas Data Syiah di Indonesia, Bynahimunkar.com on 13 September 2013.

153 Muhammad Thalib, Syi'ah : Menguak Tabir Kesesatan dan Penghinaannya Terhadap Islam, (Yogyakarta: El-Qossam, 2007), hlm. 196. 
Rifa'i Abubakar, Syamsul Anwar dan Haedar Nashir : Gerakan Syi'ah Mempertahankan Eksistensinya dalam Konstelasi Politik Keagamaan Di Indonesia

ajaran mereka. ${ }^{154}$ Faktor lain, karena umat Islam Sunni tidak dapat membedakan antara tokoh Islam Syi'ah dengan bukan Syi'ah, karena tokoh Syi'ah tidak menampakkan diri mereka sebagai orang Syi'ah. Mereka bersembunyi dibalik strategi taqiyah. Betapa tidak orang-orang Islam di sebagian daerah Kepulauan Riau, secara turun-temurun memperingati hari Asyura, tanpa mengetahui asal-usul ritual peringatan itu.

Implikasi perbedaan tentang doktrin bahwa Syi'ah menganggap ajaran Sunni tidak mewakili ajaran keluarga (ahlulbait) Nabi Muhammad SAW. Sebaliknya menurut Sunni doktrin Syi'ah telah menyimpang dari ajaran Islam yang benar. Hadis dalam perspektif Syi'ah hanya diterima melalui riwayat ahlulbait. Syi'ah mendasarkan hadis dari Imam-imam mereka, dan semua ucapan para Imam Ahlulbait as adalah hadis. ${ }^{155}$

Menurut Vali Nasr perbedaan Sunni-Syi'ah merupakan masalah penting dalam Islam yang bersimpang jalan dan masing-masing memandang dirinya sebagai kepercayaan yang murni. Perbedaan ini menyangkut pemahaman sejarah Islam, teologi, hukum dan juga keyakinan. ${ }^{156}$ Tanpa kepemimpinan (imamah) yang benar menurut Syi'ah, maka agama akan kehilangan arti dan tujuannya dan perbedaan itu juga dalam masalah politik. ${ }^{157}$

Dalam Fatwa MUI Pusat tahun 1984 disebutkan bahwa paham Syi'ah sebagai salah satu paham agama yang terdapat

${ }^{154}$ Mamduh Farhan al-Buhari, Gen Syi'ah: Sebuah Tinjauan Sejarah, Penyimpangan Akidah dan Konspirasi Yahudi, Judul asli: al-Syi'ah Minhum 'Alaihim, Penerjemah:Agus Hasan Bashari, ( Jakarta: Darul Falah, 2001),hlm. 77.

155 Nashir Makarim Syirazi, Inikah Keyakinan Kita, (Pekalongan: Mu'ammal, 2007), hlm. 54.

156 Vali Nasr, Kebangkitan Syi'ah: Islam, Konflik dan Masa Depan, Judul Asli: The Shia Revival, How Conflicts within Islam Will Shape the Future, Penerjemah: M. We Murteza, (Jakarta: Diwan Publishing, 2007), hlm. 31.

157Vali Nasr, Kebangkitan Syi'ah: Islam, Konflik dan........., hlm. 37. 


\begin{abstract}
Rifa'i Abubakar, Syamsul Anwar dan Haedar Nashir : Gerakan Syi'ah Mempertahankan Eksistensinya dalam Konstelasi Politik Keagamaan Di Indonesia

dalam dunia Islam mempunyai perbedaan pokok dengan Islam Sunni Indonesia. ${ }^{158}$ Oleh karena itu MUI Pusat menghimbau kepada umat Islam Sunni agar meningkatkan kewaspadaan terhadap pengaruh paham Syi'ah. Terbitnya buku"Mengenai dan Mewaspadai Penyimpangan Ajaran Syi'ah di Indonesi", telah memicu semakin gencarnya penolakan terhadap keberadaan Syi'ah di Indonesia.
\end{abstract}

Menurut Karl Marx bahwa suatu kelas benar-benar eksis ditengah masyarakat, apabila ada kesadaran sedang berkonflik dengan kelas-kelas lain. Jika tidak muncul kesadaran berkonflik tersebut, maka hanya akan eksis dalam dirinya sendiri. Oleh karena itu untuk menjadi kelas yang eksis tidak dapat dihindari adanya konflik. ${ }^{159}$ Potensi konflik itu akan semakin tinggi apabila kelas tersebut berada dalam masyarakat yang pluralistik atau multikulturalistik, karena adanya kompetisi untuk memperoleh sesuatu yang menjadi kepentingannya. 160

Konflik Syi'ah dengan Sunni sudah dimulai sejak kedatangan Islam. Misi Islam yang lebih dahulu dibawah oleh orang-orang Syi'ah ke Aceh kemudian disusul oleh kelompok Ahlus Sunnah ke Peureulak secara rahasia. Dengan kekuatan pengikut inilah kemudian memberontak terhadap pemerintahan Sulthan Alaidin Saiyid Maulana yang berakhir dengan kemenangan kelompok Ahlus Sunnah dan dengan

158 MUI, Himpunan Fatwasejak 1975, (Jakarta:Penerbit Erlangga,2011), hlm. 93.

${ }^{159}$ George Ritzer dan Douglas J. Goodman, Teori Sosiologi Dari Teori Klasik Sampai Perkembangan Mutakkhir Teori Sosial Postmodern, terj. Nurhadi, (Yogyakarta: Kreasi Wacana, 2008), hlm. 65.

160J.Dwi Narwoko-Bagong Suyanto, (ed), Sosiologi Teks Pengantar dan Terapan, (Jakarta: Kencana, 2004), hlm. 97. 
Rifa'i Abubakar, Syamsul Anwar dan Haedar Nashir : Gerakan Syi'ah Mempertahankan Eksistensinya dalam Konstelasi Politik Keagamaan Di Indonesia

demikian berakhirlah kekuasaan Dinasti Arab Qurays yang beraliran Syi'ah.

Sistem kepercayaan sebagai kerangka pikir primordial setiap etnisitas dan agama merupakan kebanggaan etnis dan identitas religius, ia adalah masalah pengorbanan diri dan kelompoknya untuk membela harga diri dan kehormatan. Menurut Cliford Geerts sistem kepercayaan digolongkan sebagai model perilaku manusia. Oleh karena itu sistem kepercayaan mengambil bagian penting dalam setiap konflik agama-etnis. ${ }^{161}$

Faktor utama pemicu konflik adalah perbedaan prinsip ajaran agama yang merupakan warisan sejarah, yang kemudian memunculkan sikap saling menghina dan merendahkan masing-masing kelompok. Konflik ini lebih mengarah pada agama, jika ada konflik kearah politik itu merupakan implikasi dari konflik ajaran yang prinsip. Ada perbedaan perlakuan politik agama antara kelompok Sunni dengan Syi'ah. Negara melalui Kementerian Agama tidak memperlakukan kelompok Syi'ah secara khusus, seperti memberikan bantuan finansial melalui dana APBN untuk aktivitas organisasi Syi'ah, pembinaan sumber daya manusia dan tidak memperlakukan secara istimewa tokoh-tokoh Syi'ah. Namun negara tidak melarang keberadaan Syi'ah di Indonesia. Berbeda dengan perlakuan negara terhadap kelompok Sunni yang diwakili oleh organisasi Muhammadiyah, NU dan lainlain.

${ }^{161}$ Masdar Helmy, Rekonstruksi Paradiogma Teori dan resolusi Konflik Agama-Etnik, dalam Thoha dkk, Resolusi Konflik Islam Indonesia, (Yogyakarta: Lembaga Studi Agama dan Sosial, IAIN Sunan Ampel dan Lembaga Kajian Islam dan Sosial, 2007), hlm. 30-32. 
Rifa'i Abubakar, Syamsul Anwar dan Haedar Nashir : Gerakan Syi'ah Mempertahankan Eksistensinya dalam Konstelasi Politik Keagamaan Di Indonesia

Implikasi dari konflik Sunni-Syi'ah adalah Syi'ah semakin menyadari bahwa keberadaannya selalu mengancam kerukunan internal umat Islam. Oleh karena itu orang-orang Syi'ah memilih menerapkan ajaran taqiyah untuk menjaga kokohnya Negara Kesatuan Republik Indonesia, memperkuat konsolidasi internal dan memperkuat peran mereka dalam berkontribusi bagi pembangunan bangsa agar dengan demikian jasa-jasa mereka menjadi sulit untuk dilupakan oleh negara.

\section{Integrasi}

Hubungan Sunni-Syi'ah mengalami pasang surut karena konflik. Pemulihan hubungan dilakukan melalui integrasi dan kerjasama. Oleh karena itu banyak potensi yang dapat menjadi perekat Sunni-Syi'ah. Salah satu potensinya adalah bahwa jika kaum Syi'ah mengakui Sunni sebagai mazhab dalam Islam seharusnya mereka menghormati Indonesia sebagai Negara Muslim Sunni. Itulah jalan damai, kecuali apabila Syi'ah melihat muslim Sunni adalah aliran sesat yang wajib di-Syi'ahkan. ${ }^{162}$

Usaha Syi'ah untuk menjalin hubungan dan bekerjasama dengan kelompok Islam lainnya menunjukkan bahwa Syi'ah lebih mengedepankan integrasi. Karena konflik justru kontraproduktif dengan semangat ukhuwah Islamiyah. Jalaluddin Rahmat Ketua Dewan Syuro IJABI memilih PDIP sebagai kendaraan politik setidak-tidaknya untuk memperkuat posisi Syi'ah. Integrasi Syi'ah sudah dilakukan dengan semua komponen umat Islam Indonesia, utamanya

162Adian Husaini, dalam Islamia, Jurnal Pemikiran Islam Republika, 19 Januari 2002. 
Rifa'i Abubakar, Syamsul Anwar dan Haedar Nashir : Gerakan Syi'ah Mempertahankan Eksistensinya dalam Konstelasi Politik Keagamaan Di Indonesia

dengan mempraktekkan ajaran takiyah, sehingga sulit bagi masyarakat umum untuk mengenal orang-orang Syiah. 163

Proses integrasi Syi'ah-Sunni dapat diketahui dari tidak ditemukannya perkampungan Syi'ah, kecuali di Sampang Madura ada perkampungan kecil yang khusus dihuni oleh warga Syi'ah. Secara umum warga Syi'ah hidup menyebar ditengah-tengah warga Sunni, berbaur, bahkan melakukan perkawinan dengan warga sunni. Dalam pergaulan di masyarakat Syi'ah tidak ekskelusif, tidak ada pakaian khusus warga Syi'ah dan kekuatan yang dimiliki Syi'ah adalah berbasis intelektual (Hawzah) dan spiritual (Husainiyah). ${ }^{164}$ Pendekatan kepada tokoh-tokoh Islam Sunni untuk memberikan pemahaman bahwa Syi'ah bukan musuh Sunni, musuh yang sebanarnya adalah zionis. Syi'ah terbuka kepada semua golongan umat Islam dan mempunyai hubungan sosial yang baik dengan lingkungan. 165 Ada beberapa contoh kesamaan budaya Syi'ah dengan tradisi warga Nahdlatul Ulama, seperti peringatan haul, acara tahlilan yang banyak dilakukan oleh warga NU, sesungguhnya serupa dengan upacara-upacara Syi'ah. Warga NU juga menghindari menikahkan anak pada hari Asyura yang merupakan hari kesedihan memperingati syahidnya Imam al-Husein, cucu Nabi SAW. Dikalangan NU dibacakan salawat Dibb yang

163 Rausyan Muthahhari Ketua IJABI DIY, Wawancara tanggal 10 Juni 2016 di kediaman beliau Kabupaten Sleman DIY.

164 A.M Sofwan, Ketua Yayasan Rausyan Fikri Yogyakarta, yang beralamat di Jalan Kaliurang Sleman DIY, Wawancara tanggal 23 Juni 2014, pukul 12.00-13.00.

165Thoha al-Musawi Pengelola Pondok Pesantren al-Hadi, Wawancara tanggal 8 Agustus 2014 pukul 13.00 di Pondok Pesantren al-Hadi Pekalongan Jateng. 
Rifa'i Abubakar, Syamsul Anwar dan Haedar Nashir : Gerakan Syi'ah Mempertahankan Eksistensinya dalam Konstelasi Politik Keagamaan Di Indonesia

menyebutkan nama-nama Imam Syi'ah dan keistimewaan Ahlulbait. 166

Dengan menggunakan berbagai referensi Syi'ah, menunjukkan ada pengakuan sumber referensi Syi'ah oleh kelompok Sunni. Eksistensi Syi'ah sebenarnya tidak dapat dilepaskan dari peran muslim tradisional Indonesia yang secara tidak sadar ikut mempertahankan kebiasaan yang pada awalnya merupakan pengaruh Syi'ah, seperti kebiasaan mengajar ngaji di beberapa daerah di Jawa dan Madura masih cukup banyak yang menyebut tanda harakat seperti bahasa Persia Jabar, Jer (Zher), Pes (Fyes) dan bukan bahasa Arab: Fathah, Kasroh, Dommah. ${ }^{167}$ Bukti diterimanya IJABI oleh sebagian organisasi Islam, adalah dilakukannya kerjasama antara IJABI dengan Dewan Masjid Indonesia yang berhasil memprakarsai berdirinya Majelis Sunni-Syi'ah Indonesia (MUHSIN), sebagai bentuk forum dialog dan upaya untuk menggerakkan kegiatan sosial kemasyarakatan dalam membangun umat. ${ }^{168}$

\section{PENUTUP}

Gerakan sosial dan keagamaan di Indonesia cenderung dinamis untuk bertahan dalam pergulatan sosial kemasyarakatan. Kecenderungan itu didasarkan pada filosofi ketika kelompok itu didirikan. Gerakan Syi'ah mempertahankan eksistensinya dalam konstelasi politik keagamaan di Indonesia memperjuangkan pembentukan

1665yafiq Basri Assegaf, Menelisik Syi'ah, Kompas Edisi 03-01-2012.

167 Ishomuddin, Diskursus Politik Dan Pembangunan, Melacak ... ....,hlm. 112 .

$168 \mathrm{Abu}$ Mujahid, Jejak Langkah Syiah di Indonesia, dalam AsySyariah, Ilmiah diatas Sunnah, Majalah, diterbitkan oleh Oase Media, Yogyakarta : Banyuraden, Gamping, Sleman DIY, Vol.VIII/No.92/1434 H/2013 M, hlm. 45. 
Rifa'i Abubakar, Syamsul Anwar dan Haedar Nashir : Gerakan Syi'ah

Mempertahankan Eksistensinya dalam Konstelasi Politik Keagamaan Di Indonesia

masyarakat Syi'ah (Corak non politik) dan negara Islam Syi'ah (Corak politik) dengan model gerakan intelektual, gerakan spiritual dan gerakan ideologis.

Gerakan Syi'ah mempertahankan eksistensinya dalam konstelasi politik keagamaan di Indonesia, menunjukkan intensitas yang signifikan, utamanya setelah masa reformasi 1998, yang menempatkan ajaran Islam Syi'ah sebagai ideologi gerakan yang sangat kuat dipegang oleh pengikut Islam Syi'ah. Kendati secara teologis Syi'ah ditentang oleh kaum Sunni, tetapi tetap bertahan (eksis), karena Syi'ah mampu mengkonstruksikan dirinya untuk bertahan dengan memperbesar kontribusi dalam membangun sumber daya manusia Indonesia dan memperkokoh soliditas internal dan membangun kerjasama dengan kelompok Islam lainnya. Secara teologis tidak seluruh paham keagamaan Syi'ah berbeda dengan paham keagamaan Islam Sunni. Ada kesamaan dalam bermazhab yaitu sama-sama penganut mazhab Syafi'i. Dengan demikian tidak semua aspek ajaran Islam Syi'ah ditentang oleh Islam Sunni, akan tetapi masih ada yang dapat diterima keberadaannya. Syi'ah juga mampu membangun jaringan struktural sampai ke tingkat bawah, hidup dalam budaya masyarakat majemuk yang toleran, serta mampu beradaptasi dengan dinamika perbedaan. Dinamika konflik telah mewarnai gerakan Syi'ah dalam mempertahankan eksistensinya, akan tetapi daya integrasinya lebih kuat, karena banyaknya faktor pengikat yang terpenuhi atau dengan kata lain daya konflik lebih rendah dari pada daya integrasi.

Secara sosiologis, Syi'ah eksis karena: Pertama, pergulatan baik dalam bidang pendidikan, kaderisasi, sosial, agama, budaya maupun politik yang berlangsung cukup lama, 
Rifa'i Abubakar, Syamsul Anwar dan Haedar Nashir : Gerakan Syi'ah Mempertahankan Eksistensinya dalam Konstelasi Politik Keagamaan Di Indonesia

sejak Syi'ah masuk ke Indonesia, bahkan cenderung semakin terbuka dan berkembang. Kedua, Integrasi sosial budaya. Akulturasi budaya Syi'ah dengan budaya Islam Indonesia mampu merekatkan hubungan kedua komunitas Islam tersebut. Syi'ah mampu mengeksiskan dirinya dalam aspek: (1). Kelembagaan atau Organisasi. Bahwa organisasi Syi'ah Indonesia yang sangat eksis adalah Ahlu Bait Indonesia (ABI) dan Ikatan Ahlul Bait Indonesia (IJABI) (2). Ajaran teologi atau paham keagamaan. (3). Anggota atau jamaah dari 1.000.000 (satu juta) orang, menjadi 2.500.000 (Dua juta lima ratus ribu ) orang.

Sejak Syi'ah masuk ke Indonesia telah bergulat dalam konflik yang berakibat terjadi peperangan yang mengharuskan pembagian wilayah kekuasaan. Konflik Sunni-Syi'ah disebabkan oleh perbedaan pandangan keagamaan, kepentingan-kepentingan berbeda yang tidak dapat disatukan dan lemahnya perlindungan negara terhadap umat beragama. Hubungan Sunni dan Syi'ah Indonesia mengalami pasang surut. Keharmonisan hubungan Sunni dan Syi'ah terhambat oleh faktor konflik.

Dalam hal integrasi sosial budaya, akulturasi budaya Syi'ah dengan budaya Islam Indonesia mampu merekatkan hubungan kedua komunitas Islam tersebut. Demikian pula pembauran antara orang-orang Syi'ah dengan orang-orang Islam Sunni dalam pergaulan sehari-hari. 
Rifa'i Abubakar, Syamsul Anwar dan Haedar Nashir : Gerakan Syi'ah

Mempertahankan Eksistensinya dalam Konstelasi Politik Keagamaan Di Indonesia

\section{DAFTAR PUSTAKA}

Ahmadi, Abu, Psikologi Sosial, Jakarta: Rineka Cipta, 1999.

Arikunto, Suharsimi, Prosedur Penelitian Suatu Pendekatan Praktek, Jakarta: Rineka Cipta, 2001.

Burhan M. Bungin, Penelitian Kualitatif: Komunikasi, Ekonomi, Kebijakan Publik, dan Ilmu Sosial, Jakarta: Kencana Prenama Media Group, 2007.

Gulo, W, Metodologi Penelitian, Jakarta: Grasindo, 2004.

Haedar, Nashir, Islam Syariat: Reproduksi Salafiyah Ideologis di Indonesia, Bandung: PT Mizan Pustaka, 2013.

Hasymi, A, Sejarah Masuk dan Berkembangnya Islam di Indonesia, Bandung: PT Al-Ma'arif, 1989.

Ishomuddin, Diskursus Politik Dan Pembangunan, Melacak Arkeologi dan Kontroversi Pemikiran Politik Islam, Malang: UNMUH Malang, 2001

Jamil, M.Yunus, Tawarikh Raja-raja Kerajaan Aceh, Banda Aceh: Ajdam I Iskandarmuda, 1968.

Jatmika, Sidik, Genk Remaja: Anak Haram Sejarah ataukah Korban Globalisasi? Yogyakarta: Penerbit Kanisius, 2010.

J. Dwi Narwoko-Bagong Suyanto, (ed), Sosiologi Teks Pengantar dan Terapan, Jakarta: Kencana, 2004.

Mathew B, at. al, Analisis Data Kualitatif, Jakarta: UI Press, 1992.

Muhadjir, Noeng, Metodologi Penelitian Kualitatif, Edisi III,Yogyakarta: Rake Sarasin, 1998.

Mamduh Farhan al-Buhari, Gen Syi'ah: Sebuah Tinjauan Sejarah, Penyimpangan Akidah dan Konspirasi Yahudi, Judul asli: alSyi'ah Minhum 'Alaihim, Penerjemah:Agus Hasan Bashari, Jakarta: Darul Falah, 2001.

M. Attamimy, Syi'ah, Sejarah, Doktrin, Perkembangan di Indonesia, Yogyakarta: Graha Guru, 2009. 
Rifa'i Abubakar, Syamsul Anwar dan Haedar Nashir : Gerakan Syi'ah Mempertahankan Eksistensinya dalam Konstelasi Politik Keagamaan Di Indonesia

Mulyana,Yahya, Elit Masyarakat Sipil dan Politik Lokal: Studi Tentang Gerakan Sosial Pembentukan Provinsi Banten, Tesis S-2 Ilmu Politik PPs UGM, 2001.

MUI, Himpunan Fatwa Sejak 1975, Jakarta: Penerbit Erlangga, 2011.

M. As'ad El Hafidy, Aliran-Aliran Kepercayaan dan Kebatinan di Indonesia, Jakarta: Ghalia Indonesia, 1982.

Okbah, Farid Ahmad, Ahlussunnah Waljama'ah dan Dilema Syi'ah di Indonesia, Jakarta: Perisai Qur'an, 2013.

Poloma, Margaret M, Sosiologi Komtemporer, Jakarta: PT Raja Grafindo Persada, 1994.

Ramadhan, Abdul Chair, Membangun Politik Hukum Sistem Ketahanan Nasional Terhadap Ancaman Ekspansi Ideologi Transnasional Syi'ah Iran, Surakarta: Disertasi Program Pascasarjana Program Doktor Ilmu Hukum UNS, 2015, Tidak diterbitkan.

Ridwan, M. Deden, Tradisi Baru Penelitian Agama Islam: Tinjauan Antardisiplin Ilmu, Bandung: Nuansa, 2001.

Rahnip M, Aliran Kepercayaan dan Kebatinan Dalam Sorotan, Surabaya: Pustaka Progressif, 1987.

Ritzer, George and Douglas J.Goodman, Teori Sosiologi dari Teori Sosiologi Klasik Sampai Perkembangan Muta'khir Teori Sosial Postmodern, Yogyakarta: Kreasi Wacana, 2008.

Sarantakos, Sotirios, Social Research, Melbourne: Mac Millan Education Australia PTY LTD, 1993.

Syirazi, Nashir Makarim, Inikah Keyakinan Kita, Pekalongan: Mu'ammal, 2007.

Soekanto, Soerjono, Faktor-faktor Dasar Interaksi Sosial dan Kepatuhan pada Hukum, Jakarta: t.tp, 1974.

, Sosiologi Suatu Pengantar, Edisi Baru Ketiga, Jakarta: Raja Grafindo, 1993. 
Rifa'i Abubakar, Syamsul Anwar dan Haedar Nashir : Gerakan Syi'ah

Mempertahankan Eksistensinya dalam Konstelasi Politik Keagamaan Di Indonesia

Suyanto, Bagong, Sutinah, (Ed), Metode Penelitian Sosial, Berbagai Alternatif Pendekatan, Jakarta: Prenada Media Grouf, 2007.

Thoha dkk, Resolusi Konflik Islam Indonesia, Yogyakarta: Lembaga Studi Agama dan Sosial, IAIN Sunan Ampel dan Lembaga Kajian Islam dan Sosial, 2007.

Thalib, Muhammad, Syi'ah: Menguak Tabir Kesesatan dan Penghinaannya Terhadap Manusia,Yogyakarta: El-Qossam, 2007.

Vali Nasr, Kebangkitan Syiah : Islam, Konflik dan Masa Depan, Judul Asli: The Shia Revival, How Conflicts within Islam Will Shape the Future, Penerjemah : M. We Murteza, Jakarta: Diwan Publishing, 2007.

Young, Kimbal dan Raymond W, Mack, Sociologi and Social Life, New York: American Book Company, 1959.

\section{Majalah, Jurnal:}

Majalah Asy-Syariah, diterbitkan oleh Oase Media, Yogyakarta.

Kompas Edisi 03-01-2012.

Jurnal Multikultural dan Multi religius. 